\title{
EL DESCUBRIMIENTO DE UN JADE OLMECA EN LA ISLA DE COZUMEL, QUINTANA ROO, MÉXICO
}

\author{
Por el Dr William L. RATHJE de la \\ Universidad de Arizona, el Dr. Je- \\ remy A. SABLOFF de la Universidad \\ de Harvard y Prof. David A. GRE- \\ GORY del New England College.
}

Desde 1972, arqueólogos de la Universidad de Arizona y del Museo Peabody de la Universidad de Harvard, han estado investigando en la Isla de Cozumel, Quintana Roo, México, que se encuentra frente a la Costa Este de Yucatán. Este proyecto arqueológico se lleva a cabo bajo los auspicios de esas instituciones y en colaboración con el Instituto Nacional de Antropología e Historia de México. El trabajo ha sido patrocinado también por la National Geographic Society y por donadores privados e institucionales y es codirigido por los autores de este artículo.

El personal del trabajo de campo incluye estudiantes de las Universidades de Arizona y de Harvard, del New England College de Hennicker, de la Universidad de Wesleyan y de la Universidad de Stanford, así como personal cozumeleño.

El proyecto se inició para intentar esclarecer el papel del comercio a larga distancia durante el desarrollo y auge de la civilización maya. Los resultados de las temporadas de trabajo 1972-1973 han proporcionado una valiosa información que ha capacitado a los arqueólogos para mejor comprender el papel crucial que presentaron los antiguos comerciantes mayas, siglos antes de la conquista española.

Las recientes excavaciones en la isla de Cozumel produjeron el hallazgo de un jade olmeca labrado, el cual fue encontrado en un contexto espacial y temporalmente singular. Una detallada descripción del objeto y de su contexto, será seguida de una breve discusión sobre las implicaciones de tal descubrimiento.

La pieza labrada es un pendiente de las siguientes medidas: $6.8 \mathrm{~cm}$ de altura, $5.5 \mathrm{~cm}$ de ancho y $1.8 \mathrm{~cm}$ de grueso. Consiste en una 
cabeza labrada en relieve, circundada por una corona con tres apéndices mellados y dos apéndices más no mellados. Los elementos de un motivo de banda celeste incisos en la corona sobre la parte superior de la cabeza, forman otra cabeza estilizada. Cada uno de los apéndices tiene a su vez una cabeza incisa, llegando el total de cabezas en el pendiente a siete, número mágico en la mayoría de las religiones mesoamericanas.

La técnica especial de labrado y taladrado, y las caras con sus curvadas fauces de jaguar, ojos oblicuos y cabeza hendida son características del estilo del arte olmeca. Otros objetos ejecutados en este estilo puro han sido fechados con certeza como pertenecientes al Preclásico Medio (1 200-600 a.C.) en el área Tabasco-Veracruz en la Costa del Golfo de México.

El pendiente fue encontrado en una tumba burdamente construida, en el sitio San Gervasio, un gran centro de población disperso en el centro de la isla de Cozumel. Nuestro trabajo en San Gervasio ha revelado que mientras la mayoría de los restos datan del periodo Posclásico (900-1519 d.C.), hay una secuencia hacia atrás hasta el Preclásico Tardío (300 a.C.).

Una de las áreas que ha producido los restos más tempranos es el Grupo VI, donde una plataforma hecha de piedras sin labrar, soporta en su parte superior siete plataformas más pequeñas. Las estructuras que alguna vez fueron colocadas en la parte superior están casi totalmente destruidas debido a la acción centenaria de las raíces de ramón y de otros árboles grandes que cubren toda el área. Solamente dos de las plataformas más pequeñas conservan restos de estructuras identificables y fue precisamente frente a una de ellas en donde la fosa conteniendo el jade fue descubierta. Esta fue construida en el relleno de la plataforma que soporta a la estructura VI-C, aproximadamente a $70 \mathrm{~cm}$ bajo el nivel del piso e inmediatamente frente a la estructura. Tres pisos de estuco en cercana proximidad vertical y todos en relación con la construcción de la Estructura VI-C estaban precisados con piedras pequeñas y tierra conteniendo gran cantidad de tepalcates.

Bajo la parte superior de la fosa y alrededor de ella había grandes piedras sin labrar y el relleno contenía pocos tepalcates. La fosa no tenía cubierta de piedras planas y tampoco evidencia de piso. Entre las lajas toscamente cortadas que formaban los lados de la fosa se encontraron los restos de dos individuos, en un deplorable estado de conservacion; pero parece que uno de los cuerpos estaba flexionado y otro era un entierro secundario. 
Los objetos encontrados en la tumba incluyen: dos cuentas largas y curvas de concha; dos aros grandes de concha grabados con círculos; otras cuentas surtidas de collar de jade y el pendiente olmeca. Fueron encontradas al menos dos vasijas completas pero rotas y grandes fragmentos de una tercera vasija, todas asociadas directamente con el entierro.

La cerámica incluye también un plato policromo de las Tierras Bajas del Sur, que está fechado en el Clásico Temprano (Periodo Temprano I), de 300 a 600 d.C.; un jarro monocromo y un plato policromo trípode de la misma zona, los cuales provienen del periodo Clásico Tardío (600-800 d.C.). El relleno encontrado alrededor de la tumba contenía pedacería de barro Puuc, por lo que se fecha hacia 600-1000 d.C. En consecuencia el entierro puede ser del final del Periodo Clásico, quizá efectuado alrededor de 800 d.C.

El hallazgo del pendiente fue especialmente significativo para el proyecto por el interés que este tiene en definir la posición de Cozumel en el sistema comercial Pan-Yucateco y, como un nuevo dato para fechar el desarrollo de la ruta marítima en torno a la Península de Yucatán. Los arqueólogos piensan que exactamente en este lugar debe haberse producido un importante cambio de rutas comerciales terrestres a rutas marítimas, durante el periodo Clásico Tardío y que este cambio provocó un cambio mayor en el modo de vida de la antigua Mesoamérica.

Las excavaciones efectuadas durante el proyecto ofrecen evidencia de población en Cozumel desde el periodo Preclásico hasta la conquista española, dato que contrasta marcadamente con los existentes en la costa oriental de Yucatán, justamente 15 millas distante de Cozumel a través del canal, y en donde una muy pequeña actividad transcurre hasta el Posclásico Tardío (según comunicación personal de W. y T. Andrews).

De hecho, el relleno de la pequeña plataforma que soporta a la Estructura VI-C es un muestrario de tepalcates del Preclásico y del Clásico Temprano.

La presencia del pendiente muestra que en los tiempos del Clásico Tardío, Cozumel no era un lugar apartado, sino que estaba ligado por mar, mediante el intercambio comercial a larga distancia cuando menos de algunos artículos, y aunque fuera solamente a través del canal que lo separa de Yucatán. Habría sido extraño sin duda, que un pendiente tan fino hubiera recorrido una distancia de mil kilómetros por vía terrestre para llegar a una isla pequeña y pobre en recursos, si ésta no fuera parte de un importante sistema comercial 
o una ruta marítima, pero su descubrimiento añade un elemento más para entender el desarrollo de las rutas comerciales marítimas.

El hallazgo es también importante porque relaciona el área olmeca y el área maya directamente. Desde los descubrimientos precursores de Matthew Stirling en los sitios olmecas de Tres Zapotes y la Venta hace más de tres décadas, la relación entre las dos culturas ha sido fuente de constantes debates. La edad de estas dos culturas fue fijada en una conferencia a mediados de los años cuarenta, en la cual se estableció para la cultura olmeca una anterioridad de 1000 años. De cualquier forma, el aparente origen olmeca de los jeroglíficos usados por los mayas así como otras similitudes, además de la aparente Pan-Mesoamericana presencia olmeca han provocado que la interrogante sobre la relación entre mayas y olmecas sea aún más estimulante.

Revisando estos hechos, algunos jades olmecas, posiblemente procedentes de Yucatán han sido reportados por los arqueólogos. Todos son de una calidad muy pobre, con un trabajo manual muy burdo y su estilo no es puro. Ninguno de ellos tiene una procedencia arqueológica espécífica. La única pieza de uso para el enigma es una lanceta de jade para extraer sangre, similar en forma a tipos olmecas, la cual fue encontrada en una ofrenda Preclásica en el sitio de Seibal al sur de las Tierras Bajas.

La pieza de Cozumel se encontró en un indudable contexto Clásico tardío Maya, su estilo es incuestionablemente olmeca y por su manufactura ha sido fechada en el Preclásico.

Existen muchas explicaciones para esta mezcla disonante. El pendiente debe haber sido conservado como una herencia por treinta o cuarenta generaciones. Debe haber sido originalmente saqueado de alguna tumba olmeca de Veracruz. Cualquiera que sea su origen, es evidente que jades olmecas estaban en circulación en el área maya durante el Clásico Tardío. Además, es muy significativo que el hallazgo de un valioso objeto, íntimamente ligado con los iniciadores de la primera ruta comercial Pan-Mesoamericana ocurriera en Cozumel.

Finalmente, la pieza es única porque es un verdadero objeto artístico y uno de los más hermosos jades descubiertos en toda Mesoamérica. De estos jades mesoamericanos, es además uno de los pocos que presentan un contexto bien documentado. Piezas como ésta son blanco de los saqueadores de todo el mundo (hombres que arrancan los objetos de su contexto como una langosta es arrancada de su concha). Afortunadamente, el pendiente de jade de Cozumel fue des- 
cubierto por arqueólogos y muy pronto será exhibido por el Instituto Nacional de Antropología e Historia.

Por lo tanto, éste es uno de los raros descubrimientos que aunan un valor estético y uno científico. Con esto en mente, la importancia del hallazgo puede ser fácilmente apreciada. 


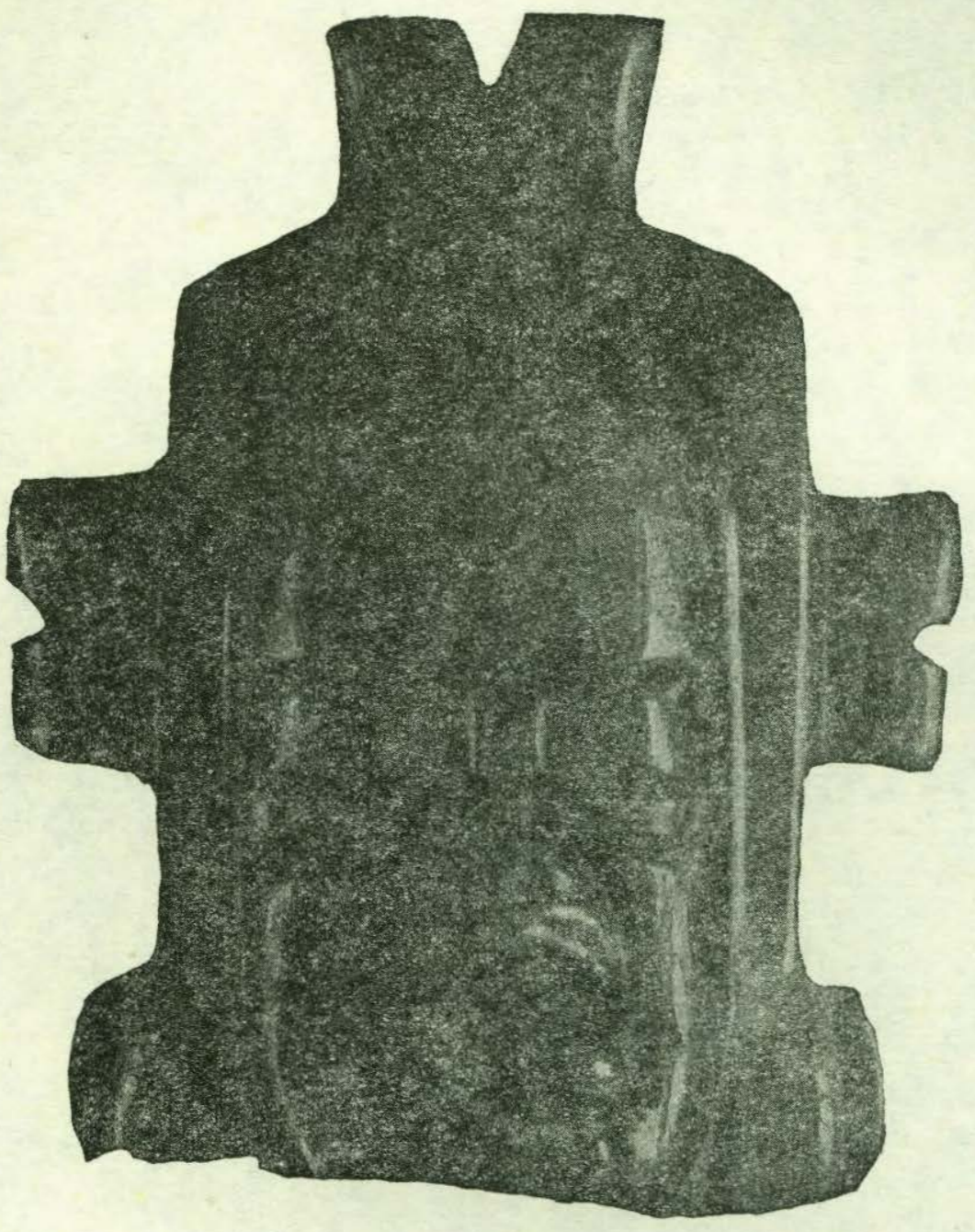

Estudios de Cultura Maya. Vol. IX, 1973

Instituto de Investigaciones Filológicas/

Facultad de Filosofía y Letras, UNAM 

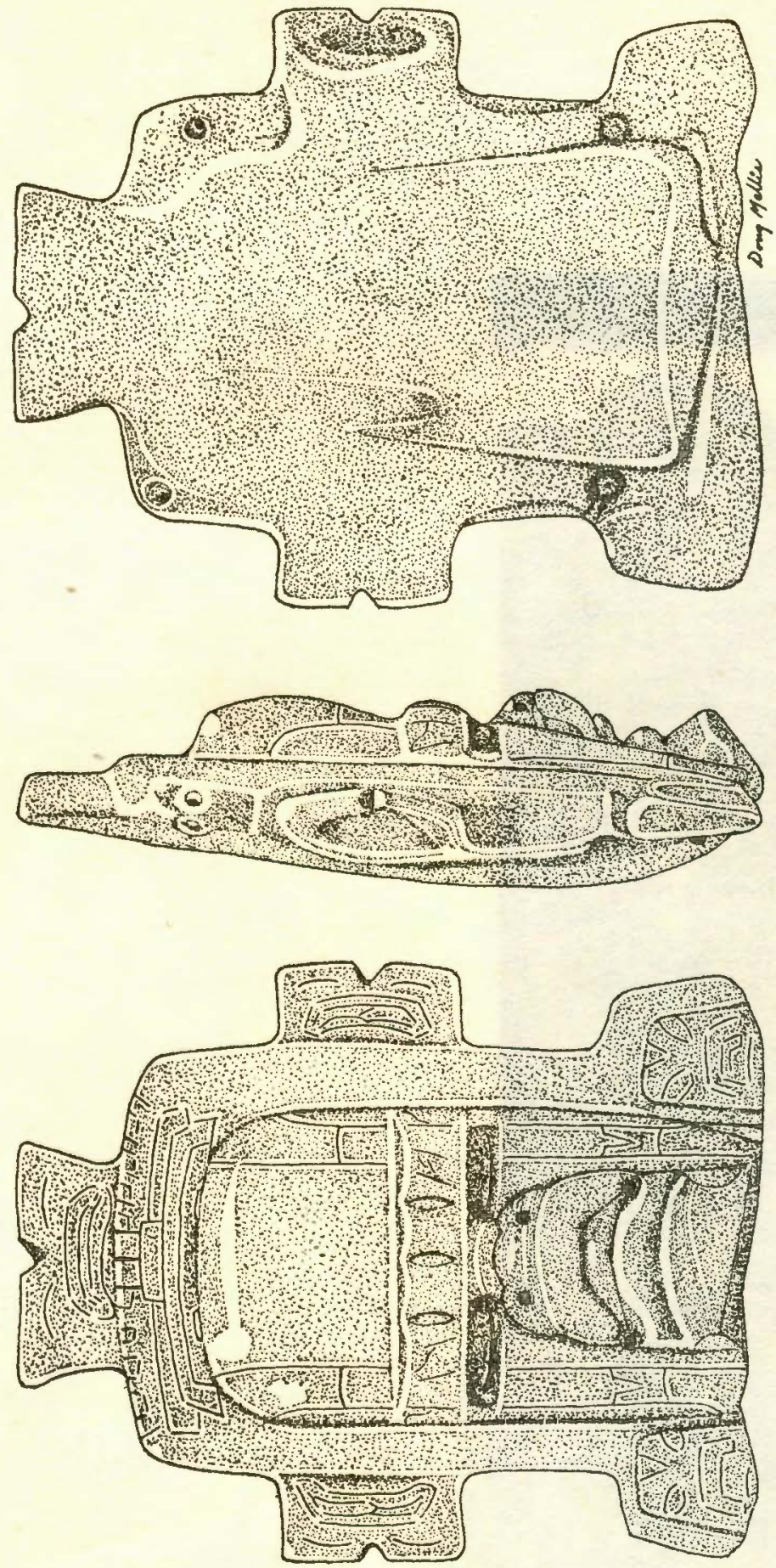

Estudios de Cultura Maya. Vol. IX, 1973

Instituto de Investigaciones Filológicas/

Facultad de Filosofía y Letras, UNAM

http://www.iifilologicas.unam.mx/estculmaya/ 